Acta Crystallographica Section D

Biological

Crystallography

ISSN 0907-4449

\title{
Crystallization and preliminary crystallographic studies of the D59A mutant of MicA, a YycF response-regulator homologue from Streptococcus pneumoniae
}

\section{Alan Riboldi-Tunnicliffe, Marie-Claude Trombe, ${ }^{\text {b }}$ Colin J. Bent, ${ }^{\mathrm{c}}$ Neil W. Isaacs ${ }^{\mathrm{c} *}$ and Timothy J. Mitchell ${ }^{\mathrm{a}}$}

\begin{abstract}
a IBLS, Division of Infection and Immunity, University of Glasgow, Glasgow G12 8QQ, Scotland, 'baboratoire de Genétique et Physiologie Bactérienne, E.A. 3036, Centre Hospitalo Universitaire de Rangueil, Université Paul Sabatier, 31403 Toulouse CEDEX, France, and ${ }^{\mathrm{c}}$ Department of Chemistry, University of Glasgow, Glasgow G12 8QQ, Scotland
\end{abstract}

Correspondence e-mail: neil@chem.gla.ac.uk

RR02 (MicA) is an essential bacterial protein that belongs to the YycF family of response regulators and consists of two domains: an $\mathrm{N}$-terminal receiver domain and a C-terminal effector domain. Streptococcus pneumoniae RR02 (MicA; residues 2-234) has been crystallized using the sitting-drop vapour-diffusion technique. The crystals belong to space group $P 2_{1}$, with unit-cell parameters $a=46.46$, $b=32.61, c=63.35 \AA, \beta=90.01^{\circ}$. X-ray diffraction data have been collected to $1.93 \AA$ resolution.

\section{Introduction}

Streptococcus pneumoniae is a bacterial pathogen responsible for diseases such as pneumonia, bacteraemia and meningitis and is a leading cause of illness and death in infants, the elderly and immunocompromised patients (AlonsoDeVelasco et al., 1995). Many strains of S. pneumoniae are becoming resistant to a wide range of antibiotics, including vancomycin and erythromycin, and new targets for antimicrobial agents are being sought.

Among such targets are the two-component signal-transduction systems, 13 of which exist in S. pneumoniae (Lange et al., 1999). The majority of two-component systems (TCS) consist of two distinct protein components: a histidine protein kinase (HPK) and a cytoplasmic response regulator (RR). The latter has two distinct domains: a receiver domain, which accepts the phosphoryl group from the HPK on an aspartic acid, and a DNA-binding domain, which controls gene expression (Stock et al., 1995). RR02 (MicA), a $26 \mathrm{kDa}$ responseregulator protein, has been shown to be essential for bacterial growth. Knockout mutations in these genes lead to non-viable bacterial strains, thus making this a prime target for new antibacterial agent design (Brown et al., 2000; Lange et al., 1999; Throup et al., 2000). It has been shown that the twocomponent signal-transduction system HK02/ RR02 is involved in competence repression under oxygen-limiting environments and was thus named Mic (microareobiosis control; Echenique \& Trombe, 2001). It was proposed that the histidine kinase HK02 system contains a PAS domain, classically involved in redox reactions and in the protection of the cell against oxidative stress, in particular by repression of competence (Echenique et al., 2000). Under oxygen-limiting conditions, the HK02 histidine kinase sensor phosphorylates RR02 (MicA) on a highly conserved aspartate residue in the presence of magnesium ions, which in turn regulates the transcription of ComCDE (Echenique \& Trombe, 2001) by an uncharacterized mechanism. The transfer of a phosphate group from HK02 to both the wildtype and mutant proteins was possible. However, mutation of Asp59 to Ala59 appears to destabilize the bond between Asp52 and phosphate: in the wild-type protein the half-life of RR02- $\mathrm{PO}_{4}$ was $20 \mathrm{~min}$, whilst for the mutant (RR02-D59A-PO ${ }_{4}$ ) the half-life was $12 \mathrm{~min}$ (Echenique \& Trombe, 2001).

In this paper, we report the cloning, purification, crystallization and preliminary crystallographic analysis of the RR02-D59A (MicA-D59A) mutant from S. pneumoniae.

\section{Materials and methods}

\subsection{Protein expression and purification}

The DNA coding for residues 2-234 of the mutated response regulator RR02 (MicA) was cloned into the pET33b vector (Novagen), which utilizes the T7lac promoter to drive recombinant protein overexpression (Echenique \& Trombe, 2001). Expression plasmids were transformed into Escherichia coli BL21 (DE3) host strain (Stratagene) using a heatshock technique. Several 11 batches of LBenriched growth media (Sigma) containing $100 \mu \mathrm{g} \mathrm{ml}^{-1}$ ampicillin were inoculated with $10 \mathrm{ml}$ of an overnight culture. The cultures were shaken at $200 \mathrm{rev} \mathrm{min}^{-1}$ at $310 \mathrm{~K}$ until an $\mathrm{OD}_{600}$ of 0.5 was reached. IPTG (Melford) was then added to a final concentration of $1 \mathrm{~m} M$ in each culture to initiate overexpression of the RR02 (MicA) mutant. After induction, cells were allowed to grow for an additional $3 \mathrm{~h}$ at $310 \mathrm{~K}$, harvested by spinning the cells at $5000 \mathrm{~g}$ for $15 \mathrm{~min}$ at $277 \mathrm{~K}$ and resuspended in a buffer containing $25 \mathrm{mM}$ Tris $\mathrm{pH} 7.5,4 \mathrm{~m} M$ imidazole and $200 \mathrm{mM} \mathrm{NaCl}$. Cells were lysed by sonication on ice $(6 \times 30 \mathrm{~s})$ and centrifuged at $30000 \mathrm{~g}$ for $1 \mathrm{~h}$ to remove the insoluble fraction. The RR02 (MicA) mutant was puri-
(C) 2004 International Union of Crystallography Printed in Denmark - all rights reserved 


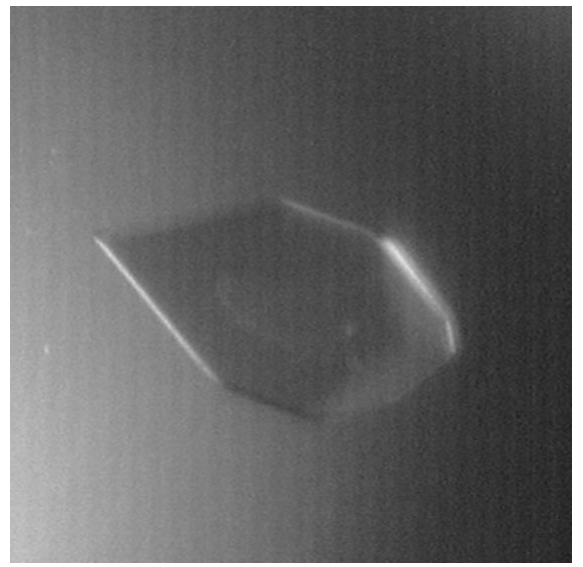

Figure 1

Single crystal of RR02-D59A grown from condition No. 23 of the PEG/Ion screen (Hampton Research).

fied by Ni-affinity chromatography. The protein was loaded slowly (overnight at $277 \mathrm{~K}$ ) onto a column previously equilibrated with buffer $A$ (4 $\mathrm{m} M$ imidazole, $25 \mathrm{~m} M$ Tris, $200 \mathrm{~m} M \mathrm{NaCl} \mathrm{pH}$ 7.5) before elution at room temperature using a linear gradient of $0-100 \%$ buffer $B$ (1 $M$ imidazole, $25 \mathrm{~m} M$ Tris, $200 \mathrm{~m} M \mathrm{NaCl} \mathrm{pH}$ 7.5). The protein was further purified by gel filtration using a Superdex-75 column previously equilibrated in buffer $C(25 \mathrm{~m} M$ Tris, $300 \mathrm{~m} M \mathrm{NaCl} \mathrm{pH}$ 7.5). Fractions containing the pure His-tagged protein were concentrated to between 5 and $10 \mathrm{mg} \mathrm{ml}^{-1}$ in an Amicon pressure cell before being used in crystallization trials.

\subsection{Crystallization and data collection}

Trials were set up using sitting-drop and hanging-drop vapour-diffusion techniques at both 277 and $293 \mathrm{~K}$. The protein was mixed with the reservoir solution in a 1:1 ratio to produce 4 or $6 \mu$ drops. Crystals unsuitable for diffraction were observed in a number of conditions after several days. A single crystal was observed after six months in condition No. 23 of the PEG/Ion screen; the reservoir contained $200 \mathrm{~m} M$ ammonium formate, $20 \%(w / v)$ PEG 3350 pH 6.6 (Fig. 1). Owing to the length of time taken to grow the initial crystal, no optimization was possible prior to data collection. The crystal was flash-cooled
Table 1

Data-collection statistics for RR02-D59A.

Values in parentheses are for the highest resolution shell.

\begin{tabular}{ll}
\hline Source & $\begin{array}{l}\text { XRD-1, ELETTRA, } \\
\text { Trieste }\end{array}$ \\
Wavelength $(\AA)$ & 1.0 \\
Resolution $(\AA)$ & $63.0-1.93$ \\
Space group & $P 2_{1}$ \\
Unit-cell parameters $\left(\AA{ }^{\circ}{ }^{\circ}\right)$ & $a=46.46, b=32.61$, \\
Molecules per AU & \multicolumn{1}{c}{$c=63.35, \beta=90.01$} \\
Solvent content $(\%)$ & 36.05 \\
$R_{\text {sym }}$ & $0.087(0.361)$ \\
$\langle I / \sigma(I)\rangle$ & $5.3(2.0)$ \\
Total No. reflections & 152223 \\
No. unique reflections & 14491 \\
Average redundancy & $5.1(4.2)$ \\
Completeness $(\%)$ & $98.7(95.4)$ \\
\hline
\end{tabular}

using dried paraffin oil as the cryoprotectant (Riboldi-Tunnicliffe \& Hilgenfeld, 1999) and an almost complete data set was collected from a native crystal (Fig. 1), which diffracted to beyond $2.0 \AA$ on beamline XRD-1 at ELETTRA, Trieste with a fixed wavelength of $1.0 \AA$. Data were collected at a detector distance of $140 \mathrm{~mm}$ from the crystal, with each frame being $1^{\circ}$ in width. Owing to a fall in the intensity of the beam during data collection, the data were collected in three batches. Data were processed to a maximum resolution of $1.93 \AA$ A using MOSFLM (v.6.2.2; Leslie, 1992) and scaled using SCALA (Evans, 1993) and TRUNCATE (Collaborative Computational Project, Number 4, 1994). A summary of the crystallization conditions and $\mathrm{X}$-ray datacollection statistics is given in Table 1 .

\section{Results and discussion}

Crystals of RR02 (MicA) measured $0.1 \times$ $0.1 \times 0.08 \mathrm{~mm}$ (Fig. 1) and diffracted to $1.93 \AA$ resolution. With one monomer in the asymmetric unit, the determined Matthews coefficient is $1.94 \AA^{3} \mathrm{Da}^{-1}$ (Matthews, 1968) and the solvent content is $36.05 \%$. A data set with a completeness of $98.7 \%$ and an $R_{\text {sym }}$ of $0.087 \%$ was collected (full data-processing statistics can be found in Table 1).

As the $\beta$ angle is very close to $90^{\circ}$, the data were processed in several space groups including the orthorhombic space groups $P 222, P 222_{1}, P 22_{1} 2_{1} 2, P 2{ }_{1} 2_{1} 2_{1}, C 222$ and
$C 222_{1}$ and the primitive monoclinic space groups $P 2$ and $P 2_{1}$. The merging statistics after SCALA (Evans, 1993) were much better in $P 2_{1}$ than for the other space groups. Attempts are now under way to determine the structure by molecular replacement using as starting models RR02-Rec determined recently in our laboratory and the E. coli OmpR effector domain (Kondo et al., 1997; PDB code 1odd).

We would like to thank the beamline staff at XRD1, ELETTRA for help and support during data collection. This work was supported by EC grant QLRK2-2000-00542 and a grant from the BBSRC.

\section{References}

AlonsoDeVelasco, E., Verheul, A. F. M., Verhoef, J. \& Snippe, H. S. (1995). Microbiol. Rev. 59, 591-601.

Brown, J. R., Holmes, D. J., Rosenberg, M. \& Burnham, M. K. (2000). Mol. Microbiol. 35, 566-576.

Collaborative Computational Project, Number 4 (1994). Acta Cryst. D50, 760-763.

Echenique, J. R., Chapuy-Regaud, S. \& Trombe, M.-C. (2000). Mol. Microbiol. 36, 688-696.

Echenique, J. R. \& Trombe, M.-C. (2001). J. Bacteriol. 183, 4599-4608.

Evans, P. R. (1993). Proceedings of the CCP4 Study Weekend. Data Collection and Processing, edited by L. Sawyer, N. Isaacs \& S. Bailey, pp. 114-122. Warrington: Daresbury Laboratory.

Kondo, H., Nakagawa, A., Nishihira, J., Nishimura, Y., Mizuno, T. \& Tanaka, I. (1997). Nature Struct. Biol. 4, 28-31.

Lange, R., Wagner, C., de Saizieu, A., Flint, N., Molnos, J., Stieger, M., Caspers, P., Kamber, M., Keck, W. \& Amrein, K. E. (1999). Gene, 237, 223-234.

Leslie, A. G. W. (1992). Jnt CCP4/ESF-EAMCB Newsl. Protein Crystallogr. 26, 27-33.

Matthews, B. W. (1968). J. Mol. Biol. 33, 491-497.

Riboldi-Tunnicliffe, A. \& Hilgenfeld, R. (1999). J. Appl. Cryst. 32, 1003-1005.

Stock, J. B., Surette, M. G., Levit, M. \& Park, P. (1995). Two-Component Signal Transduction, edited by J. A. Hoch \& T. J. Silhavy, pp. 25-52. Washington DC, USA: ASM Press.

Throup, J. P., Koretke, K. K., Bryant, A. P., Ingraham, K. A., Chalker, A. F., Ge, Y., Marra, A. \& Wallis, N. G. (2000). Mol. Microbiol. 35, 566-576. 